The University of San Francisco

USF Scholarship: a digital repository@ Gleeson Library | Geschke Center

2015

\title{
Ecology Postdocs in Academia: Primary Concerns and Possible Solutions
}

\author{
A. K. Shaw \\ D. E. Stanton \\ S. R. Supp \\ A. Budden \\ S. Eby
}

See next page for additional authors

Follow this and additional works at: http://repository.usfca.edu/biol_fac

Part of the Biology Commons, and the Ecology and Evolutionary Biology Commons

\section{Recommended Citation}

Shaw, A. K., Stanton, D. E., Supp, S. R., Budden, A., Eby, S., Reynolds, P. L., Salguero-Gómez, R., Scholes, D. R. and Zimmerman, N. B. (2015), Ecology Postdocs in Academia: Primary Concerns and Possible Solutions. The Bulletin of the Ecological Society of America, 96: 140-152. http://dx.doi.org/10.1890/0012-9623-96.1.140 
Authors

A. K. Shaw, D. E. Stanton, S. R. Supp, A. Budden, S. Eby, P. L. Reynolds, R. Salguero-Gómez, D. R. Scholes, and Naupaka B. Zimmerman 


\section{Ecology Postdocs in Academia: Primary Concerns and Possible Solutions}

Allison K. Shaw, ${ }^{1}$ Daniel E. Stanton, ${ }^{2}$ Sarah R. Supp,${ }^{3}$ Amber Budden, ${ }^{4}$ Stephanie Eby, ${ }^{5}$ Pamela L. Reynolds, ${ }^{6}$ Roberto Salguero-Gómez, ${ }^{7}$ Daniel R. Scholes, ${ }^{8}$ Naupaka B. Zimmerman ${ }^{9}$

${ }^{1}$ Division of Evolution, Ecology and Genetics, Research School of Biology, The Australian National University, Canberra ACT 0200, Australia and Department of Ecology, Evolution, and Behavior, University of Minnesota, St. Paul, Minnesota 55108 USA

${ }^{2}$ Division of Plant Sciences, Research School of Biology, The Australian National University, Canberra ACT 0200, Australia and Department of Ecology, Evolution, and Behavior, University of Minnesota, St. Paul, Minnesota 55108 USA

${ }^{3}$ Department of Geography, University of Wisconsin-Madison, 550 North Park St., Madison, Wisconsin 53706 USA

${ }^{4}$ DataONE, University of New Mexico, 1312 Basehart SE, Albuquerque, New Mexico 87106 USA

${ }^{5}$ Department of Biology, College of the Holy Cross, Worcester, Massachusetts 01610 USA

${ }^{6}$ Department of Environmental Science and Policy, University of California, Davis, One Shields Avenue, Davis California 95616 USA

${ }^{7}$ Centre for Biodiversity and Conservation Science, The University of Queensland, St Lucia Queensland 4072 Australia

${ }^{8}$ School of Integrative Biology, University of Illinois at Urbana-Champaign, Urbana, Illinois 61801 USA

${ }^{9}$ School of Plant Sciences, University of Arizona, Tucson, Arizona 85721 USA

\section{Introduction}

The postdoctoral research phase is intended to allow researchers to further develop and strengthen skills needed to succeed in an academic career (NAS et al. 2000). For example, doctoral programs train students to conduct research and publish papers, but often do not include opportunities to develop professional skills, such as project management, balancing multiple research projects, applying for large grants, managing research teams, teaching, and developing the mentorship skills necessary for future careers both within and outside of academia. Many postdoctoral positions, however, do allow early-career researchers to practice these skills sets while deepening their research skills and expanding their collaboration network. Thus, job candidates that have postdoctoral experience are often viewed as more competitive in the academic market (Nerad 1999). For these reasons, and because the ratio of Ph.D.s to available academic positions is increasing (Schillebeeckx et al. 2013), postdoctoral positions have nearly become a prerequisite for modern careers in ecology. The postdoctoral phase is clearly an important, and potentially exciting, time to develop the skills needed to succeed in an academic career. Yet the uncertainty of advancing successfully to the next career stage 
and the temporary nature of postdoctoral positions in ecology (typically 1-3 years) represent strong stressors on individual researchers and may have negative impacts on motivation, productivity, and personal health (Helbing et al. 1998, Gloria and Steinhardt 2014).

Postdoctoral researchers face a suite of concerns that differ from graduate students, including: learning to manage multiple projects, obtaining and giving adequate mentorship, applying for new postdoctoral, faculty, or non-academic positions, and negotiating benefits for those positions. In addition, postdoctoral researchers sometimes lack the financial support that graduate students receive from their advisers, departments, larger granting agencies, or local communities, and while not eligible for student discounts, typically do not have their own grants to help defray conference or publication costs. The short-term nature and myriad formats of postdoctoral appointments in ecology make it difficult to establish a system of unified support for this scientific demographic. In many institutions, the graduate program oversees postdoctoral researchers, yet postdocs are not entitled to all of the student benefits and may receive appointments akin to temporary contractors with limited oversight, benefits, and compensation.

With increasing competition on the job market, it is not uncommon for Ph.D.s to complete multiple postdoctoral appointments, which leads to moving more than once during the time between the completion of graduate school and obtaining a permanent position. The peripatetic nature of this career phase presents significant challenges at both the personal and professional level. It can disrupt family dynamics, remove both social and professional support networks, increase stress, and reduce productivity (Arnold 2014). For many researchers, the postdoctoral stage falls during the age at which individuals are most likely to experience major life changes, such as becoming parents, or needing to care for aging relatives. These life changes often present further constraints to mobility.

These factors can lead to a postdoc "holding pattern" phenomenon - a feeling of being caught in an endless cycle in the pursuit of a continually moving target. These concerns are not unique to postdocs in ecology, but represent a larger set of issues facing early-career scientists across all disciplines (Helbing et al. 1998). Concerns and complaints about challenges facing postdoctoral researchers are a frequent topic of conversation among early-career scientists; debates regularly surface on the ecology listserv Ecolog-L regarding support for postdocs and the current ecology job market. To address whether these individual exchanges reflect the perceptions of the ecology community as a whole, we conducted an online survey to determine which (if any) aspects of the postdoc stage are of greatest concern to the ecology community. The survey was followed by a workshop at the 2013 Annual Meeting of the Ecological Society of America (ESA) in Minneapolis, Minnesota, where we encouraged participants to identify issues of concern to postdocs as well as possible solutions. Our goal was to generate specific recommendations to address postdoc concerns that could be implemented by the ecological community and postdoctoral researchers themselves, with support from the structure provided by ESA. These measures would build on support already available to both students and earlycareer researchers (e.g., the ESA student section, workshops and panels at the annual ESA Meeting).

Methods

Survey 
Based on conversations with colleagues, we identified nine primary challenges facing postdocs: (1) career advice and support, (2) employment opportunities, (3) gender- and/or minority-specific support, (4) life balance (including dual careers, family, etc.), (5) mentoring (both receiving and providing), (6) non-salary financial support (independent research, travel to conferences, etc.), (7) professional networking, (8) professional training, and (9) salary. We also identified five potential entities who could be involved in addressing the perceived challenges: (1) individual postdocs, (2) postdocs' academic advisers, (3) postdocs' academic institutions, (4) professional societies like ESA, and (5) ecologists as a community. Although we recognize that the career pathways are quite variable within and beyond academia, for the purpose of this report we restricted the survey to support for postdocs within the academic framework, with the goal that future assessments could identify issues and solutions for the broader ecology postdoc community.

In June 2013, we created an anonymous survey with seven questions (see Box 1 for full survey) using Qualtrics, an online survey service provided through the University of Minnesota, to address the components detailed above. Completion of this survey took $\sim 10$ minutes. The survey was directed at "anyone who self-identifies as part of the ecology community" and was distributed via Ecolog-L ( $\sim 17,000$ subscribers from $>60$ countries), through the survey designers' professional contacts, and via social media and academic networks (e.g., Twitter, Facebook, departmental e-mails). We asked respondents to rank the nine challenges in terms of importance and the five entities in terms of their responsibility to address each challenge. We then asked respondents to enter text suggesting possible solutions. Although respondents were asked to assign each challenge to a single rank (1-9), many assigned the same rank to multiple challenges. Below we report the average weight of each challenge ( 9 minus average rank), which indicates the perceived importance of each challenge such that higher values relate to higher importance.

\section{Workshop}

We used the survey responses to structure a workshop for the ESA Annual Meeting in August 2013. The aim of the workshop, "Getting through the postdoctoral phase to an academic job," was to identify solutions and strategies to increase support for postdocs in ecology. We started the workshop with an introduction to the topic and an overview of the responses to the survey. Next, participants formed breakout groups of $\sim 8-10$ participants each to brainstorm ideas regarding solutions across the various concerns/themes. Workshop attendees with previously identified leadership skills were assigned to each group to facilitate the conversations. We provided each group with a list of suggested solutions generated from the survey responses. Each group reported their ideas and we discussed future avenues for action. Soliciting feedback on problems via the survey allowed us to convey previously discussed problems and encourage workshop participants to focus on solutions, rather than generate new issues.

\section{Results}

The survey was completed by 194 respondents ( 97 current postdocs, 32 current students, 54 professionals and faculty, 11 other). The workshop was attended by 33 participants, primarily current postdocs.

Survey respondents were asked to rank challenges (Box 1, question 2) in terms of their perception 
Box 1: Survey Questions

The survey questions below refer to the following.

- Nine areas of likely postdoc-related issues:

(1) Career advice and encouragement, (2) Employment opportunities, (3) Gender- and/or minority-specific support, (4) Life balance (including dual careers, family, etc.), (5) Mentoring (both receiving and providing), (6) Non-salary financial support (independent research, travel to conferences, etc.), (7) Professional networking, (8) Professional training, and (9) Salary.

- Five categories of potential entities who could be involved in addressing the perceived concerns:

(1) Individual postdoc, (2) Postdoc's academic adviser, (3) Postdoc's academic institution, (4) Professional society (e.g., ESA), and (5) Ecologists as a community.

Questions:

1. What is your current status (postdoc, student, professional or faculty, other)?

2. Rank the above nine issues, in terms of their importance to address, based on

1. the postdoc experience in general (asked of all respondents)

2. your specific experience as a postdoc (only asked of respondents who self-identified as "Postdoc" or "Professional")

3. Rate how involved each of the five potential entities listed above should be "'Yes, primarily," "Yes, in part," "No") in addressing concerns related to each of these four issues:

1. Mentoring (both receiving mentoring and experience providing mentoring to others)

2. Career advice and encouragement

3. Professional training

4. Non-salary financial support (independent research, travel to conferences, etc.)

4. What specifically could ecologists as a community, ESA as a society, or some combination of the two, do to address these concerns for each of these same four issues?

5. Will you be attending this workshop at ESA?

6. Are there any important concerns facing postdocs that this survey did not cover?

7. Do you have any general comments or feedback? 
a)

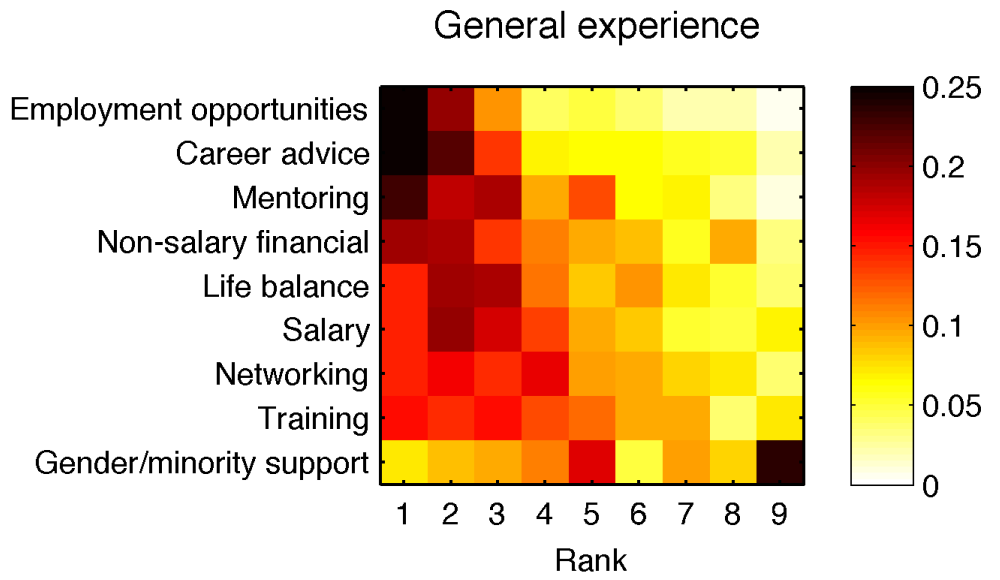

b)

\section{Personal experience}

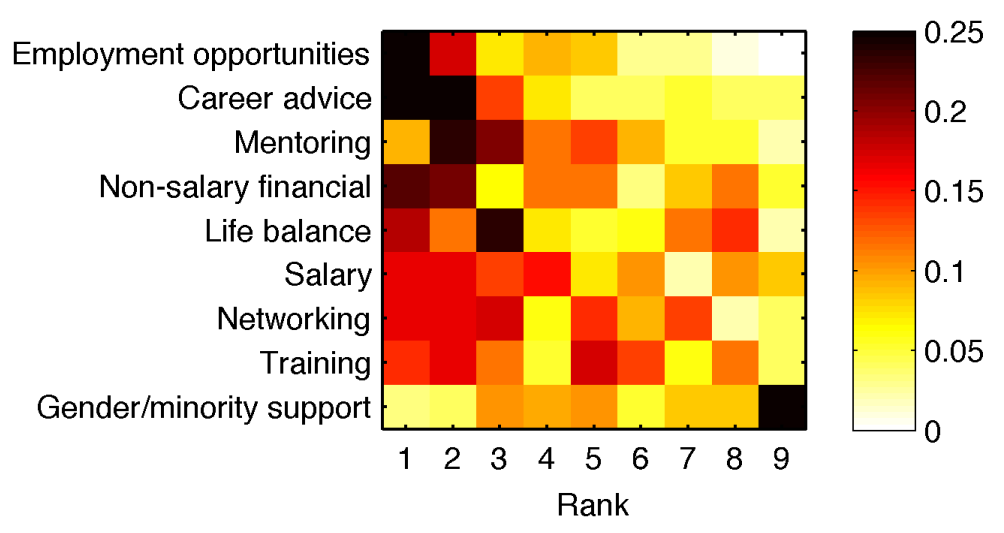

Fig. 1. Responses to survey question 2 (see Box 1). Fraction of respondents (darker colors indicate greater fractions) who assigned each rank (1-9, where $1=$ most important) to each of the nine potential issue areas. Shown are results for the respondent's perception of (a) the postdoc experience generally, and (b) his/her individual postdoc experience (only individuals who were completing or had completed a postdoc).

of the postdoc experience generally (asked of all respondents) and in terms of their own specific experience as a postdoc (asked only of respondents identifying as currently postdoc or professional). There was overall agreement between the challenges that were identified as most important for these two categories (Fig. 1a vs. 1b), with employment opportunities, career advice, and mentoring having the highest average ranks. The challenges, ranked from most to least important (Fig. 1) by survey respondents (in the two categories: general perception, personal experience), included: employment opportunities $(6.67,6.67$, respectively), career advice and encouragement $(5.84,5.96)$, mentoring 
$(5.61,5.18)$, non-salary financial support $(5.12,4.99)$, life balance $(5.11,4.82)$, salary $(5.06,4.79)$, professional networking $(4.91,4.98)$, professional training $(4.78,4.59)$, and minority support $(3.43$, 2.46).

Below we describe each of the nine challenge areas, in descending order of importance as ranked by survey respondents. For each challenge, we provide specific solutions, as proposed by both survey respondents and identified by workshop participants. The majority of challenges could be addressed in some part by the development of a centralized set of online resources. Although many of the challenges may need to be addressed at various levels of organization, we focus especially on those solutions available to ecologists as an academic community (see also Box 2).

\section{Employment opportunities}

Individuals in the ecology community may be unable to change the job market, but respondents suggested methods to improve access to employment-related resources. For example, development of a centralized online database with links to ecology-related job boards and employment announcements, fellowship deadlines, and funding and grant-writing resources could greatly improve availability and utility of existing resources. Additionally, centralized resources aimed at international postdocs would improve access for U.S. Ph.D.s wishing to go abroad and for non-U.S. Ph.D.s coming to the U.S. for their postdoc training. Many of these resources are already available, but scattered across several different specialized job boards and e-mail listservs (e.g., Ecolog-L, Physiological Ecology Section, Chronicle of Higher Education) with varying degrees of completion and redundancy. A centralized database advertised across graduate programs and professional societies could make finding jobs easier for ESA members.

Another employment challenge identified by survey respondents was the desire for longer postdoctoral contracts (3-5 years). Longer-term appointments would allow for greater stability and improved opportunities for mentoring and developing independent research projects. Appointment duration is strongly dependent on grant duration and funding cycles, but should be a consideration for PIs when applying for funding, as well as for recent Ph.D. recipients searching for postdoctoral positions.

\section{Career advice and encouragement}

Although most survey respondents believed that postdocs themselves and their advisers were primarily responsible for addressing advice-related issues, they also generally believed that institutions, professional societies, and the broader ecological community could play a more prominent role (Fig. 2a). Creating and collating information sources, as well as organizing peer groups, may be particularly helpful for early-career ESA members seeking career advice and encouragement. Peer groups and independent efforts can help early-career ecologists by organizing targeted career workshops at professional meetings. Themes suggested for these workshops (the most common solution suggested by survey respondents; $n=18$ ), included: how to be successful as a postdoc, how to create job packets for different type of jobs (e.g., faculty at a research university vs. a small liberal arts college, government or NGO research, policy or science communication), requirements for each 
a)

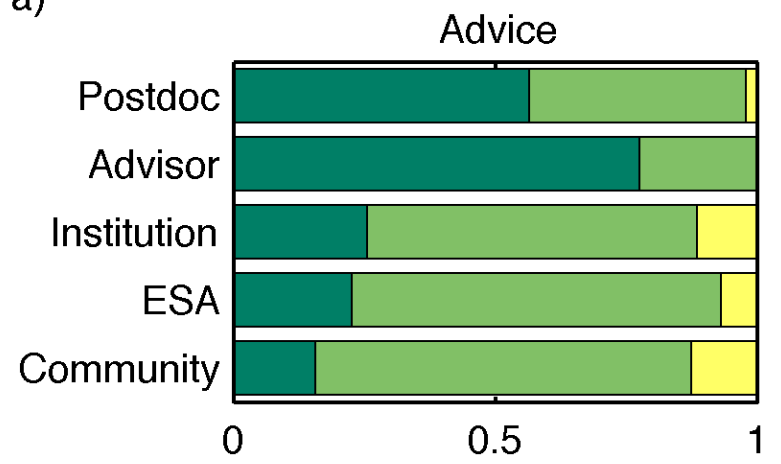

c)

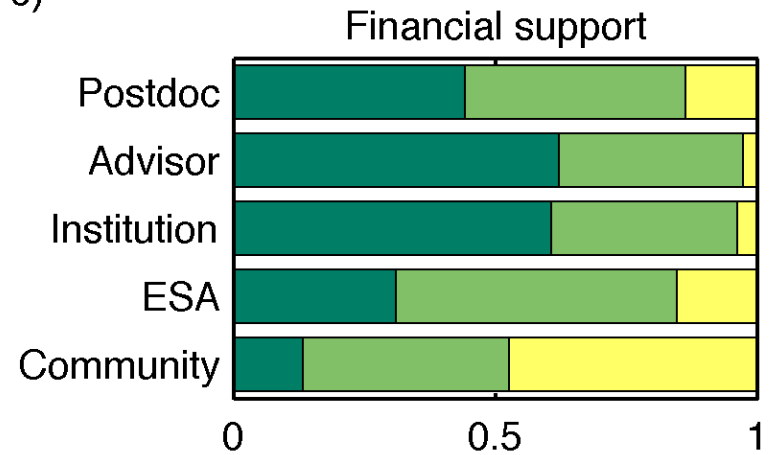

b)

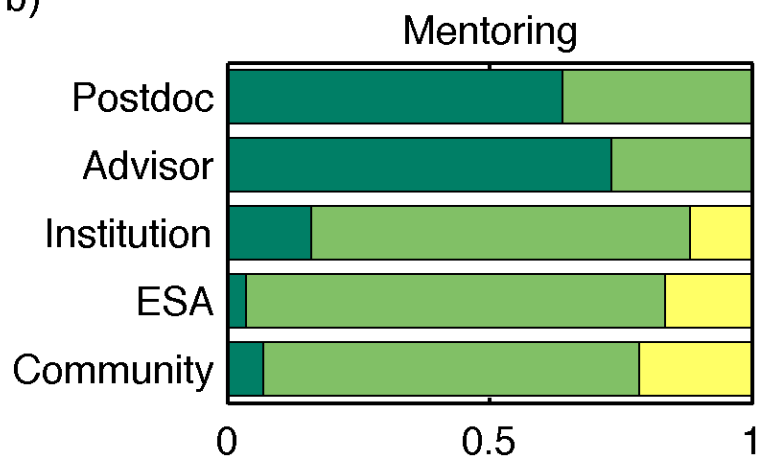

d)

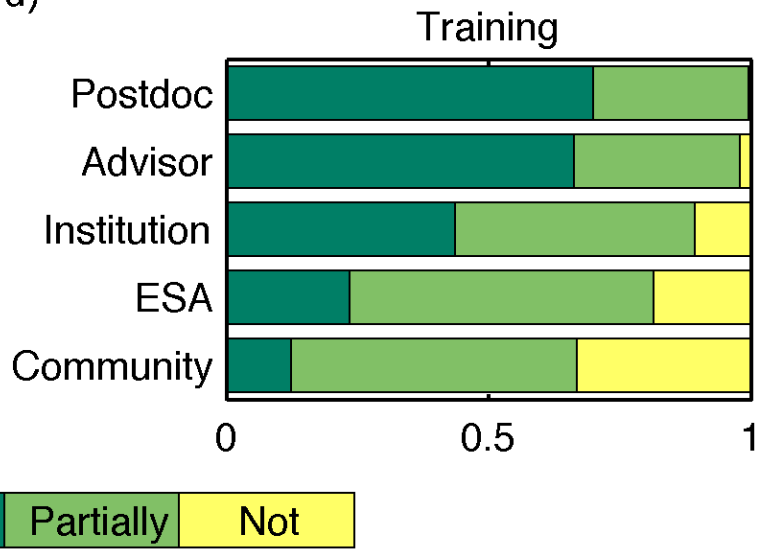

Fig. 2. Fraction of respondents who rated the ideal level of involvement of each of the five entities as primarily, partially, or not involved in addressing concerns related to (a) postdoc career advice and encouragement, (b) postdoc mentoring (both receiving mentoring and experience providing mentoring to others), (c) postdoc non-salary financial support (independent research, travel to conferences, etc.) and (d) postdoc professional training.

of these career paths (e.g., example CVs, desirable experiences and skill sets), and job statistics for career paths (number of positions available, typical number of applicants). Online resources could include how to apply for postdoc and permanent positions, interviewing advice including questions to ask potential supervisors, and links to Webinars on career development and resume-building. We are pleased to announce that one of the suggested solutions, the creation of an "Early Career" section of ESA, has now been completed (Scholes et al. 2014).

Another suggestion for community-level measures to improve career advice was developing guidelines for postdoc expectations, ideally endorsed and made publically available by ESA. These guidelines would detail expectations for postdocs themselves (fraction of time to be spent on their 
Box 2: Key Community-Level Solutions

- Form and support an ESA Early Career section (formation recently completed).

- Develop a centralized database of resources related to employment, advice and mentoring.

- Organize workshops at professional meetings with information and advice on the following topics: career paths and job availability, mentoring and mediation, work-life balance, networking, and women and minorities in science.

- Create ESA-endorsed guidelines for best practices related to the postdoc experience: what should be expected of postdocs, their advisers, and institutions?

- Strengthen mentoring programs within professional societies and sections.

- Develop a postdoc union or group to advocate for funding, benefits, postdoc PI status, etc.

- Better communicate existing versions of the above resources, where applicable.

primary research vs. side projects and professional development, responsibilities toward their lab group), expectations for postdocs' advisers (mentoring, training, funding), and expectations for the institution (postdoc orientation, supporting a postdoc association, offering postdoc teaching experience, allowing postdocs to have PI status on grants, providing funds to support publication costs for recently departed Ph.D.s and postdocs). Rather than being prescriptive, these guidelines could serve as a starting point for conversations between postdocs and their advisers. Additionally, these guidelines could be a significant resource for PIs given the growing mandates for including postdoctoral mentoring plans in grant proposals.

A third set of suggestions was to increase awareness of the challenges faced by current postdocs, and to increase visibility and clarity on the diverse career paths for ecologists. Little seems to be known about "typical" career trajectories of ecologists, but an extensive survey could be conducted to generate baseline data and to encourage sharing anecdotes and success stories (e.g., R. SalgueroGómez, unpublished data). Academic careers have progressively shifted to include more and longer career stages with little long-term security (e.g., postdocs, adjunct positions), and many respondents felt that much of the currently available advice was outdated and failed to take into account the current job market conditions.

\section{Mentoring}

Many postdocs are intermediately placed within research group hierarchies, and may serve as mentors to students (undergraduate and graduate) or to technical staff. Similar to the responses for "career advice and encouragement," most survey respondents believed that postdocs themselves and 
their advisers were primarily responsible for addressing mentoring issues (Fig. 2b). However, many respondents indicated that professional societies and the wider ecological community could provide some mentoring support.

Survey respondents and workshop participants agreed that postdoc mentoring generally needed improvement, with perceptions of low to variable support among advisers. The most common suggestions by survey respondents $(n=19)$ were to develop a set of best practice mentoring guidelines, and to strengthen mentoring programs beyond the standard postdoc-adviser relationship, e.g., through ESA sections, creating an ESA-wide mentoring program to match postdocs with junior faculty (similar to the existing SEEDS program), or creating a national ecology postdoc society. Workshops on mentoring (how to provide and receive mentoring, expectations as a mentor/mentee) and mediation (how to resolve conflicts with supervisors and coworkers) could be organized at future ESA meetings. Another suggestion was to improve peer communication and support among current postdocs to avoid a sense of isolation. Avenues could include a postdoc newsletter and forming postdoc mentoring pairs or groups.

Online resources could include mediation, mentoring advice, and guidelines. One hurdle will be determining a way to enforce stricter accountability of PIs for postdoc mentoring (e.g., requiring reporting of postdoc mentoring progress to institutions or via outcomes reports for NSF grants with postdoc mentoring plans). Although many respondents had very positive interactions with mentors, some problematic relationships were reported, and the lack of clear guidelines or venues for arbitration was considered part of the problem. This issue is likely to vary greatly among institutions.

\section{Non-salary financial support}

Most respondents believed that the advisers and institutions of postdocs were primarily responsible for addressing non-salary financial support issues, with both postdocs themselves and ESA playing a role as well (Fig. 2c). Possible solutions at the ESA level include: lower fees paid by postdocs for membership and the Annual Meeting registration, postdoc-specific travel grants, and changing the ESA journal publication fee structure to ease the financial burden on postdocs. All options raise the question of the criteria used to determine fee structure-years since Ph.D., duration at current institution, current job title, salary, or other. Alternately, an optional donation towards members of the Early Career Section with the ESA Annual Meeting registration could go towards generating funds to defray meeting costs and encourage participation of this ESA demographic.

The idea mostly commonly suggested by survey respondents $(n=31)$ for a professional society or community-level solution was the creation of a fund to support travel grants or small research grants for postdocs (e.g., a postdoc equivalent of NSF DDIGs, but with a faster turnaround to accommodate the shorter timescale of a postdoc position), and the creation of small grants that early-career researchers could apply for as postdocs for use upon securing a faculty position. As these suggestions require federal or other financial support, they may be more difficult to implement than suggestions that do not depend on monetary investment.

Online resources identifying financial support for postdocs could include lists of grants, links to 
online workshops, and other grant-writing resources. Many of these resources exist in piecemeal fashion from compilations by institutions or by individual researchers, but a centralized location for funding sources open to postdoctoral researchers (i.e., not requiring PI status) would be helpful. Although many postdocs participate in writing larger grants, they are often barred from being a lead or even co-PI either by the granting agencies or by their own academic institutions. Many participants felt that by not being a formal PI they do not receive sufficient credit or recognition for their efforts, which can be problematic when applying for tenure-track or other positions looking for evidence of prior grant success. This issue is a particularly pertinent example of the interrelatedness of the primary postdoc concerns. Many early-career ecologists recognize the importance of demonstrating research independence and individuality from their advisers for securing future employment, yet the necessary support to do so is limited.

\section{Life balance}

Work-life balance is, not surprisingly, a concern for the ecological postdoc community. In particular a number of survey respondents identified feeling more isolated during the postdoc stage than in graduate school. Increased interactions horizontally (with other postdocs across institutions) or vertically (with early-career faculty) could help alleviate these feelings. Such mentoring groups could be organized in part by the new Early Career Section. Other possible solutions include organizing workshops at future ESA meetings on time management and work-life balance, and creating a centralized online resource with advice on work-life balance. Many concerns about work-life balance often relate quite closely to not receiving or not being aware of existing support for, e.g., maternity and paternity leave, childcare resources, dual-career hiring practices, and caring for aging family members. Therefore, developing support groups and compiling resources for postdocs who: (1) are balancing dual careers and geographic limitation, (2) are parents or are thinking of having children, or (3) are caring for other family members, could be particularly useful.

\section{Salary}

Funding is a difficult challenge for the ecological community to directly address. However, one possible solution (raised by both survey respondents and workshop participants) would be to create a postdoc union or group to advocate for postdoc funding, position duration, and benefits.

\section{Professional networking}

"Professional networking" was the only issue ranked higher by individuals based on their own postdoc experience (ranked fifth) than based on their perception of the postdoc experience generally (ranked seventh). The primary suggested solution for professional networking challenges was to increase networking events at ESA and other professional meetings. One specific idea was to have a panel with ecologists who have recently successfully transitioned out of the postdoc stage. A second idea was to have a workshop or mixer featuring both "eminent" as well as "rising star" ecologists who could circulate among groups answering questions and engaging with the postdoc community.

\section{Professional training}


Training was primarily viewed as the responsibility of the postdoc and their adviser (Fig. 2d). As such, a set of best practice guidelines (mentioned under Career advice and encouragement) could help postdocs and their advisers ensure that appropriate and balanced training is received. Survey respondents most commonly $(n=33)$ expressed interest in workshops, classes, and webinars, focusing on the skills and preparation for a range of careers including non-academic ones (science communication, teaching, industry, governmental or NGO positions, etc.). Some disciplines, such as engineering, may encourage alternatives to teaching training (such as professional internships) for Ph.D. candidates who are not interested in pursuing academic careers. Given the reality that many Ph.D.s in ecology are choosing to pursue non-academic jobs, this type of experience might be important to consider in ecology programs as well.

\section{Gender-and/or minority-specific support}

Although gender and minority support was ranked last, this does not necessarily indicate that it is a minor concern. In fact, the comments by respondents indicated much overlap between this category and work-life balance challenges. Furthermore, unlike most categories, the ranking was highly bimodal (Fig. 1), with a subset of respondents ranking it as highly important, while a majority of respondents gave it little importance. Given the underrepresentation of minorities in ecological science, it is possible that this ranking reflects the composition of the respondent pool, rather than the true importance of the concern. Unfortunately, we cannot test this assumption, since survey respondents were not asked to self-report their gender, racial, or ethnic information. To address this concern, future ESA meetings could sponsor workshops on women and minorities in science. One option would be to expand the SEEDS (Strategies for Ecology Education, Diversity and Sustainability) Program, which focuses on undergraduate and graduate students, to include support for postdocs.

\section{Discussion}

Respondents to our survey ranked employment opportunities, career advice, and mentoring as their top concerns. The lack of funding opportunities, short contract durations, reduced access to the type of structure and training of Ph.D. programs, and the challenges inherent in developing an independent research presence without access to resources (both financial and institutional) afforded PIs, were all highlighted as barriers to be overcome. Clearly, the responsibility to solve these and other identified challenges is shared among individuals, professional societies, and institutions. The responses to our survey identified several paths forward for responding to the perceived challenges among earlycareer ecologists, including aggregating online resources, improving mentoring, decreasing financial burdens, and creating more spaces for networking and sharing experiences. Although our survey and workshop focused on the perceptions of ecology postdocs within an academic framework, future work should focus on non-academic pathways, as there is growing recognition that only a small fraction of doctorates eventually obtain tenure-track academic positions (Powell 2012, Sauermann and Roach 2012).

As a direct result of the survey and ESA workshop, a new section has been formed: the ESA Early Career Section (Scholes et al. 2014). The mission of this section is to provide support to early-career ecologists in transitional periods of their professional development, with a focus on individuals with 
less than eight years of full-time employment (i.e., postdoc, assistant professor, lecturer, adjunct, government employees, non-profit). This section will address the challenges facing early-career ecologists primarily at the professional society- and community level. Acting on suggestions from the community, the Section will centralize online resources (via http://esa.org/earlycareer/), provide discussion and resources via microblogging on twitter (@ESA_EarlyCareer), organize workshops and social events at the annual ESA meetings, and advocate generally for solutions to the challenges facing early-career members of ESA, including those pursuing non-academic career paths. Furthermore, these services are exactly those most likely to improve ESA membership retention after graduation (ESA 2012).

Many of the ideas suggested by survey respondents and workshop participants already exist to some extent. Each year at the Annual ESA Meeting, there are a number of career-related workshops and networking events, as well as an orientation for mentoring (through the SEEDS program). Furthermore, ESA convened an Ecology for the Next Generation committee, which recommended a number of strategies to improve support for students and early-career ecologists (http://www. esa.org/esa/?page id=7958); many of these are currently in the process of being implemented. The International Network of Next-Generation Ecologists (INNGE) has also started a compilation of resources for early-career ecologists in wiki format (http://innge.net/wiki). The University of California system has a postdoc union (http://uaw5810.org/) supporting over 6000 postdocs across a range of disciplines. ScienceCareers has developed an online tool for early-career researchers to create their own Individual Development Plan (http://myidp.sciencecareers.org/); the use of such plans is strongly encouraged by the NIH (http:/grants.nih.gov/grants/guide/notice-files/NOT-OD-13-093. $\underline{\mathrm{html}}$ ). The fact that many postdocs may not be aware of these resources emphasizes the importance of communicating existing resources as well as developing new ones.

A common theme among many survey respondents and workshop participants was a sense that postdocs seeking positions outside of academia were disadvantaged; they felt that the doctoral education system is inherently biased toward providing experience for academic career paths. These findings mesh with recent discussions on this topic, which suggest that advisers and the academic community could improve access to non-academic career skills and networking, and help change the perception of an academic career as the "gold standard" (NIH 2012). Persisting attitudes that non-academic career paths signal "failure" or "giving up" can add to early-career stressors and stifle productive solutions.

Encouragingly, survey respondents and workshop attendees were overall optimistic about finding solutions to common challenges, and felt proactive about their own role as being the most important determinant for their future (Fig. 2). For individuals to take control of their careers, however, the ecological community plays an important role in facilitating discussions and generating solutions. For example, ESA has provided support that has greatly amplified the scope and reach of activities initiated by the sections (e.g., ESA Student Section).

Many of the problems identified are not easily addressed with simple measures, and may well stem from larger challenges to academia. The term postdoc has come to describe a wide range of academic positions, each with its own responsibilities and expectations. Perhaps an easy first step 
as a community is to create a culture of laying out expectations of specific positions in advance to avoid misgivings later on. After all, many faculty members may have similar concerns regarding job security, access to research funds, and even mentoring. In our workshop we identified several concrete paths forward, and the mood of the workshop participants was cautiously optimistic, not cynical or jaded. We hope that the suggestions outlined here will spur constructive conversation and actions, and lead the ecological community towards solutions that benefit the careers and health of early-career researchers and thus, the future of the field as a whole.

\section{Contributions and acknowledgments}

AKS and DES designed/conducted the survey and analyzed results. AKS, DES, AB, and RSG along with Marissa Baskett, Scott Collins, Spencer Hall, Julie Reynolds, and Jennifer Talbot organized the ESA workshop. AKS, DES, AB, NBZ, and Marissa Baskett ran the workshop. AKS, DES, and SRS wrote the paper with contributions from SE, PLR, RSG, DRS, NBZ, and Scott Collins. We are grateful to the survey respondents and the attendees of the ESA 2013 Annual Meeting workshop for sharing their ideas.

\section{Literature cited}

Arnold, C. 2014. The stressed out postdoc. Science Careers. doi: 10.1126/science.caredit.a1400189

ESA. 2012. ESA Membership Survey, February 2011. Summary of results. ESA Bulletin 93:13-23. http://dx.doi.org/10.1890/0012-9623-93.1.13

Gloria, C. T., and M. A. Steinhardt. 2014. Relationships among positive emotions, coping, resilience and mental health. Stress and Health. http://dx.doi.org/10.1002/smi.2589

Helbing, C. C., M. J. Verhoef, and C. L. Wellington. 1998. Finding identity and voice: a national survey of Canadian postdoctoral fellows. Research Evaluation 7:53-60. http://dx.doi.org/10.1093/rev/7.1.53

NAS (National Academy of Sciences), National Academy of Engineering, Institute of Medicine. 2000. Enhancing the Postdoctoral Experience for Scientists and Engineers: A Guide for Postdoctoral Scholars, Advisers, Institutions, Funding Organizations, and Disciplinary Societies. The National Academies Press, Washington, D.C., USA.

NIH (National Institutes of Health). 2012. Biomedical Research Workforce Working Group Report. National Institutes of Health 1-156. http://acd.od.nih.gov/biomedical_research_wgreport.pdf

Nerad, M. 1999. Postdoctoral patterns, career advancement, and problems. Science 285:1533-1535.

Powell, K. 2012. The Postdoc experience: High expectations, grounded in reality. Science Careers:992-996.

Sauermann, H., and M. Roach. 2012. Science PhD career preferences: levels, changes, and advisor encouragement. PloS One 7:e36307.

Schillebeeckx, M., B. Maricque, and C. Lewis. 2013. The missing piece to changing the university culture. Nature Biotechnology 31:938-941.

Scholes, D. R., D. E. Stanton, and S. R. Supp. 2014. ESA's Early Career Ecologist Section: supporting the professional development of early career ecologists in all career trajectories. ESA Bulletin 95:435-438. 